\title{
Oxidative Stress and Dementia in Alzheimer's Patients: Effects of Synbiotic Supplementation
}

\author{
Alyne Mendonça Marques Ton, ${ }^{1}$ Bianca Prandi Campagnaro ${ }^{(D,}{ }^{1}$ Gisela Aleixo Alves, ${ }^{1}$ \\ Rafaela Aires, ${ }^{2}$ Larissa Zambom Côco, ${ }^{1}$ Clarisse Maximo Arpini, ${ }^{1}$ Trícia Guerra e Oliveira, ${ }^{1}$ \\ Manuel Campos-Toimil $\mathbb{D},{ }^{3}$ Silvana Santos Meyrelles $\mathbb{D}^{2},{ }^{2}$ Thiago Melo Costa Pereira $\mathbb{D},{ }^{1,4}$ \\ and Elisardo Corral Vasquez $\mathbb{D}^{1,2}$ \\ ${ }^{1}$ Laboratory of Translational Physiology and Pharmacology, Pharmaceutical Sciences Graduate Program, Vila Velha University, \\ Vila Velha, Espírito Santo, Brazil \\ ${ }^{2}$ Laboratory of Translational Physiology, Physiological Sciences Graduate Program, Federal University of Espírito Santo, Vitória, \\ Espírito Santo, Brazil \\ ${ }^{3}$ Pharmacology of Chronic Diseases (CDPHARMA), Molecular Medicine and Chronic Diseases Research Centre (CIMUS), \\ University of Santiago de Compostela, Santiago de Compostela, Spain \\ ${ }^{4}$ Federal Institute of Education, Science and Technology (IFES), Vila Velha, Espírito Santo, Brazil
}

Correspondence should be addressed to Bianca Prandi Campagnaro; biancacampagnaro@yahoo.com.br and Elisardo Corral Vasquez; evasquez@terra.com.br

Received 6 August 2019; Revised 8 October 2019; Accepted 18 October 2019; Published 13 January 2020

Academic Editor: Ulrich Eisel

Copyright (C) 2020 Alyne Mendonça Marques Ton et al. This is an open access article distributed under the Creative Commons Attribution License, which permits unrestricted use, distribution, and reproduction in any medium, provided the original work is properly cited.

\begin{abstract}
Background. Alzheimer's disease (AD) is the most common cause of dementia in elderly patients. Recently, several studies have shown that inflammation and oxidative stress precede the cardinal neuropathological manifestations of $\mathrm{AD}$. In view of the proven antioxidant effects of probiotics, we proposed that continuous dietary supplementation with milk fermented with kefir grains might improve cognitive and metabolic and/or cellular disorders in the AD patients. Methods. This study was designed as an uncontrolled clinical investigation to test the effects of probiotic-fermented milk supplementation ( $2 \mathrm{~mL} / \mathrm{kg} / \mathrm{daily})$ for 90 days in $\mathrm{AD}$ patients exhibiting cognitive deficit. Cognitive assessment, cytokine expression, systemic oxidative stress levels, and blood cell damage biomarkers were evaluated before (T0) and after (T90) kefir synbiotic supplementation. Results. When the patients were challenged to solve 8 classical tests, the majority exhibit a marked improvement in memory, visual-spatial/abstraction abilities, and executive/language functions. At the end of the treatment, the cytometric analysis showed an absolute/relative decrease in several cytokine markers of inflammation and oxidative stress markers $\left(\mathrm{O}_{2}^{-}, \mathrm{H}_{2} \mathrm{O}_{2}\right.$, and $\left.\mathrm{ONOO}^{-}, \sim 30 \%\right)$ accompanied by an increase in NO bioavailability (100\%). In agreement with the above findings by using the same technique, we observed in a similar magnitude an improvement of serum protein oxidation, mitochondrial dysfunction, DNA damage/repair, and apoptosis. Conclusion. In conclusion, we demonstrated that kefir improves cognitive deficits, which seems to be linked with three important factors of the $\mathrm{AD}$ - systemic inflammation, oxidative stress, and blood cell damage-and may be a promising adjuvant therapy against the $\mathrm{AD}$ progression.
\end{abstract}

\section{Introduction}

Alzheimer's disease $(\mathrm{AD})$ is the most common cause of dementia in elderly patients and is clinically defined as a progressive, global, and strong cognitive decline leading to an emotional distress and codependence [1-4]. Unfortu- nately, the number of $\mathrm{AD}$ patients has been rapidly growing worldwide (increasing by $117 \%$ in the last 26 years), with the highest age standardized prevalence in Turkey and Brazil [5].

The pathophysiology of $\mathrm{AD}$ is multifactorial, involving microglial activation, excessive proinflammatory cytokines, vascular disorder, disrupted mitochondrial function accompanied 
by overproduction of reactive oxygen species (ROS), and oxidized molecules [6-13]. In this scenario, the cardinal neuropathological manifestations of $\mathrm{AD}$ culminate with amyloid- $\beta$ $(\mathrm{A} \beta)$ and neurofibrillary tangles (NFTs) composed of hyperphosphorylated tau protein leading to synapse degeneration $[9,14,15]$.

As the actual pharmacotherapy for dementia (using cholinesterase and/or glutamate inhibitors) is insufficient in slowing down completely the AD progression, new treatment strategies are still necessary to improve $\mathrm{AD}$ patient care $[5$, 16 , 17]. In parallel, there is growing evidence that disturbances along the "brain-gut-microbiota axis" are involved in the pathogenesis of neurodegenerative diseases enhancing inflammation at the gut, systemic, and central nervous system (CNS) levels $[15,18]$. In this context, recent data have shown the beneficial effects of probiotic supplementation on intestinal epithelial integrity, immunomodulation, oxidative stress, and even procognition $[15,19,20]$. However, the role of safe and inexpensive nutraceutical synbiotic kefir (a synergistic mixture of prebiotics and probiotics) in $\mathrm{AD}$ is still not documented [15, 20, 21].

The kefir-fermented milk is a functional food originally from the Northern Caucasus and currently distributed worldwide either commercially (e.g., Russia, Spain, Germany, United States, Canada, and Brazil) or "in-house" [22-26]. Milk fermentation with kefir grains is made up by bioactive compounds (peptides, vitamins, and polysaccharides) originally generated by acid lactic bacteria and yeast species present in these grains [23, 24, 26-28]. Recently, we and others have shown that administration of kefir and/or their bioproducts was able to prevent the cardiac and vascular dysfunctions in experimental models of hypertension [23, 26, 29], atherosclerosis [30], and gastric ulcers [27], which was justified, at least in part, by its antioxidative and immunomodulatory properties.

The present study addressed the hypothesis that kefir supplementation would provide cognitive benefit by attenuating systemic inflammation and oxidative stress in $\mathrm{AD}$ patients. The novel data revealed relevant new insights into the effects of this synbiotic on cognitive function through biochemical, molecular, and cellular parameters related to neurodegenerative diseases.

\section{Methods}

2.1. Patients. This uncontrolled clinical trial evaluated AD patients selected by convenience sampling. The diagnosis of $\mathrm{AD}$ was according to the clinical diagnostic criteria of dementia due to probable Alzheimer's disease with increased level of certainty defined by the Alzheimer's Association and the National Institute on Aging (NIA) published in 2011 [31]. The criteria evaluated in our study were based on the presence of insidious cognitive progressive decline or behavior symptoms involving a minimum of two cognitive domains (e.g., memory, language, attention, and constructive abilities) besides impairment of usual activities. It is important to emphasize that unexplained symptoms by delirium or major psychiatric disorders are detected through a combination of history taking and objective cognitive assessment.
The sample included individuals of both sexes, without age restriction, who were assisted at a reference center in Vila Velha, Espírito Santo, Brazil, specialized in AD. The inclusion criteria were the following: (1) patients without previous neurological and/or psychiatric comorbidities associated with cognitive impairment, (2) patients without clinical depression and/or with a depression index $<17$ using the Hamilton scale, and (3) patients without several clinical comorbidities (decompensated diabetes) and patients with autoimmune diseases taking or not immunosuppressive medication, neoplasms, and/or inflammatory bowel diseases. The exclusion criteria were the following: (1) patients unable to make use of probiotic supplementation because of organic or environmental causes, (2) patients using substances that might affect neurocognitive assessment, and (3) patients not using the maximum dose of acetylcholinesterase inhibitor (donepezil, $10 \mathrm{mg} /$ day). The research was approved by the ethics committee of Vila Velha University (\#1.804.392), and a signed free informed consent form was obtained from each of the subjects and/or their tutors after complete information about the nature and possible risks and benefits of the study, for him/herself, the community, and medical science was given.

In the beginning of the study, thirty-four subjects fulfilled the inclusion criteria. However, eighteen subjects were excluded from the study due to the elevated depression indexes (three subjects), due to clinical and laboratory signs of decompensated diabetes (six subjects), and due to the intervention with antibiotic therapy and/or hospitalization during the follow-up (nine subjects). During the study, 3 out of 16 patients in the final group died and a total of 13 subjects completed the experiments receiving the probiotic supplementation for 90 days and being evaluated, as summarized in Figure 1.

2.2. Production of Fermented Milk by Kefir Grains. The fermented material was prepared by inoculating pasteurized milk with $4 \%$ kefir grains containing the species Acetobacter aceti, Acetobacter sp., Lactobacillus delbrueckii delbrueckii, Lactobacillus fermentum, Lactobacillus fructivorans, Enterococcus faecium, Leuconostoc spp., Lactobacillus kefiranofaciens, Candida famata, and Candida krusei and incubating the culture at $25^{\circ} \mathrm{C}-28^{\circ} \mathrm{C}$ for $24 \mathrm{~h}$. After the incubation period, the fermented product was filtered and refrigerated at $2^{\circ} \mathrm{C}-6^{\circ} \mathrm{C}$ for $24 \mathrm{~h}$, as previously described by us [23]. In order to improve organoleptic characteristics, the product was blended with organic strawberries in the proportion of $500 \mathrm{~g}$ of fruit for every $2 \mathrm{~L}$ of fermented milk without added sugars or preservatives.

2.3. Experiment Protocol. At first (T0), the participants were submitted to a battery of tests for the screening of the identification of cognitive deficits and their venous blood was collected for analysis of inflammation, oxidative stress, and molecular and cellular integrity. The blood samples were collected in EDTA-containing Vacutainer glass tubes (Becton, Dickinson and Company, Franklin Lakes, NJ) and centrifuged at $2000 \mathrm{~g}$ for $10 \mathrm{~min}$, and the serum was then stored at $-20^{\circ} \mathrm{C}$. In addition, erythrocytes were lysed and 


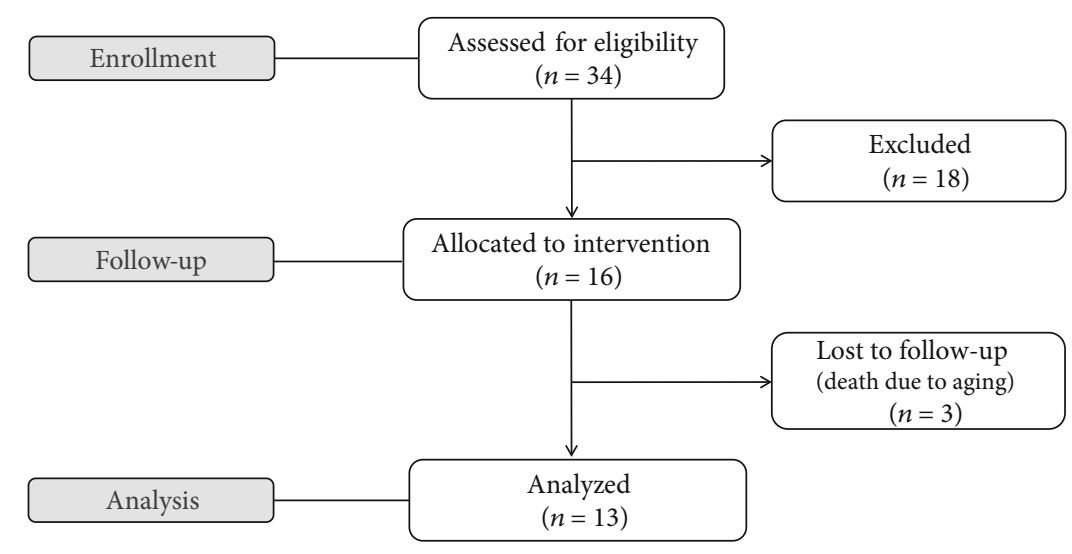

FIGURE 1: Summary of exclusion criteria used in the present study and patient flow.

white blood cells were stored at $-80^{\circ} \mathrm{C}$. All the measurements were obtained via an automatic biochemical analyzer (AU 400 or 680, Olympus/Beckman Coulter, Munich, Germany) or a flow cytometer (FACSCanto II, BD, CA, USA). These data were considered the control values in this paired study. After, the patients were subjected to fermented milk supplementation at the daily dose of $2 \mathrm{~mL}$ per kilogram of body weight. At the end of the study (T90), the cognitive, biochemical, molecular, and cellular parameters were once again evaluated.

2.4. Cognitive Assessment. Cognitive assessment was made before (T0) and after 90 days (T90) of the probiotic supplementation, using the tests recommended by the Department of Cognitive Neurology and Aging of the Brazilian Society of Neurology for screening dementia syndromes [32], as well as by the American Society of Neurology [33] and the National Institute on Aging and Alzheimer's Association [34]. The following functions were analyzed: "global cognitive functions," using the (1) Mini-Mental State Examination (MMSE); "memory," using a recall board with 10 concrete objects to promote the (2) immediate memory test and (3) delayed memory test, according to Nitrini et al. [32], which is recommended for evaluating populations with different levels of education; "visual-spatial and abstraction abilities," using the (4) Cookie Theft Picture Test, according to the consensus recommendations published by Nitrini et al. [32] suggesting the use of description of thematic figures justified by the absence of studies in the area with the Brazilian population, and the (5) Similarity Test, using the recommendations published by Nitrini et al. [32] to apply NEUROPSI subsection where the respondent is asked to say the similarity between three pairs of nouns (orange and pear, dog and horse, and eye and nose); "executive and language functions," using the (6) Boston Naming Test and (7) verbal fluency test; "attentive function," using (8) Trail Making Test A; and "visuoconstructive abilities," using the (9) clock-drawing test. To avoid the learning effect bias, the cognitive assessment trials were spaced by 90 days and the various domain tests were applied on a different order.

2.5. Determination of Cytokines Using the Cytometric Bead Array. Concentrations of proinflammatory (IL-6, IL-8, IL- 1b, IL-12p70, and TNF- $\alpha$ ) and anti-inflammatory (IL-10) cytokines were analyzed in the serum of patients using a Cytometric Bead Array Human Inflammation kit (CBA, BD Biosciences, USA) according to the manufacturer's instructions. Samples were analyzed with a FACSCanto II flow cytometer (BD, San Jose, CA, USA). Data acquisition was performed with FACSDiva software (BD), and the analysis of the events acquired was performed with the help of FCAP Array software (BD). Samples were measured by comparing them with the standard curves of recombinant cytokines using FCAP Array software (BD). All results are expressed as $\mathrm{pg} / \mathrm{mL}$.

2.6. ROS Analysis. Quantification of ROS components was also performed by flow cytometry, using a FACSCanto II (Becton Dickinson, BD, CA, USA) instrument to analyze the intracytoplasmic ROS content, as previously described by us $[27,35,36]$. Peripheral blood was drawn from the Alzheimer's patients, and the red blood cell lysis was induced by the addition of ammonium chloride. Superoxide anion $\left(\mathrm{O}_{2}{ }^{-}\right)$, hydrogen peroxide $\left(\mathrm{H}_{2} \mathrm{O}_{2}\right)$, peroxynitrite/hydroxyl radical $\left(\mathrm{ONOO}^{-} / \mathrm{OH}^{-}\right)$, and nitric oxide ( $\mathrm{NO}$ ) were monitored separately by measuring changes in median fluorescence intensity (MFI) emitted by dihydroethidine (DHE), dichlorofluorescein (DCF), hydroxyphenyl fluorescein (HPF), and diaminofluorescein (DAF), respectively. Briefly, $10^{6}$ cells were incubated with $160 \mathrm{mmol} / \mathrm{L}$ of DHE, $20 \mathrm{mmol} / \mathrm{L}$ of DCF, $10 \mu \mathrm{mol} / \mathrm{L}$ of $\mathrm{HPF}$, or $2 \mu \mathrm{mol} / \mathrm{L}$ of DAF at $37^{\circ} \mathrm{C}$ for $30 \mathrm{~min}$ (DHE, DCF, and $\mathrm{HPF}$ ) or $180 \mathrm{~min}$ (DAF) in the dark. The samples were then washed, resuspended in PBS, and kept on ice until the acquisition of 10,000 events by flow cytometry, which were subsequently analyzed using FCS Express software (De Novo).

2.7. Advanced Oxidation Protein Products. To determine advanced oxidation protein products (AOPP), $40 \mu \mathrm{L}$ of plasma diluted in PBS (1.5) was added to $10 \mu \mathrm{L}$ of $\mathrm{KI}$ $(1.16 \mathrm{~mol} / \mathrm{L})$ and $20 \mu \mathrm{L}$ glacial acetic acid and the absorbance was read at $340 \mathrm{~nm}$ in a microplate reader (Spectra-MAX190, Molecular Devices, Sunnyvale, CA, USA). The formation of triiodide ion through the oxidation of KI with chloramine-T was used to quantify AOPP levels. Data are 
expressed as $\mu \mathrm{mol} / \mathrm{mg}$ of chloramine-T per $\mathrm{mg}$ of proteins, according to Witko-Sarsat et al. [37].

2.8. Mitochondrial Membrane Potential (MMP). Estimation of mitochondrial membrane potential (MMP) was performed by flow cytometry using JC-10, a fluorogenic probe (Sigma-Aldrich, USA), following the manufacturer's instructions. Briefly, $2 \times 10^{6}$ cells were loaded with $500 \mu \mathrm{L}$ of JC-10 solution at $37^{\circ} \mathrm{C}$ for $60 \mathrm{~min}$, protected from light. For the positive control, cells were previously incubated with carbonyl cyanide 3-chlorophenyl-hydrazone (CCCP, $5 \mu \mathrm{M}$ ), while unmarked cells were set as the negative control. JC-10 forms red J-aggregates in healthy cells but stays as a green monomer in cells that have lost mitochondrial integrity. The fluorescence intensities of JC-10 aggregates (red, FL2 channel) and monomers (green, FL1 channel) were measured with flow cytometer detectors and analyzed after compensation for spectral overlap. Data are expressed as the relative aggregate/monomer (FL2/FL1) ratio, which was assumed to be proportional to MMP intensity [38].

2.9. p53 and Cleaved PARP Expression. To determine the expression of p53 and cleaved PARP, $2 \times 10^{6}$ cells were resuspended in Cytofix/Cytoperm (BD) solution and washed twice with Perm/Wash buffer (BD). Blood cells were separately incubated with $5 \mu \mathrm{L}$ of anti-p53-FITC (BD) or anticleaved PARP-PE, during $30 \mathrm{~min}$ in the dark. As the positive control, an aliquot of cells was treated with doxorubicin $(25 \mu \mathrm{g} / \mathrm{mL}$, Sigma-Aldrich, USA) before antibody incubation. For the staining control, we used specific immunoglobulins (IgG) conjugated with FITC or PE. After antibody incubation, the samples were stained with $10 \mu \mathrm{L}$ of 7 -amino-actinomycin D (7-AAD, BD). The determination of protein expression was acquired with the FACSCanto II flow cytometer (Becton Dickinson, San Jose, CA, USA) and analyzed using FCS Express software (De Novo). Data are expressed as the percentage of positive cells.

2.10. Cell Cycle Analysis. For the determination of cell cycle distribution, $2 \times 10^{6}$ cells were resuspended in Cytofix/Cytoperm (BD) solution, washed with Perm/Wash buffer (BD), and incubated with $10 \mu \mathrm{L}$ of 7-amino-actinomycin $\mathrm{D}$ (7$\mathrm{AAD}, \mathrm{BD})$ for $30 \mathrm{~min}$, at $4^{\circ} \mathrm{C}$, in the dark. The cell cycle profile was determined by the acquisition of 10,000 events per sample using the FACSCanto II flow cytometer for acquisition and the FCS Express software for analysis. The sample flow rate during acquisition did not exceed 200-300 cells per second. Data are expressed as the percentage of cells in each cell cycle phase, which are sub- $\mathrm{G}_{0}$-representing cells with fragmented DNA (DNA content $<2 n$ ), $G_{0} / G_{1}$-representing cells with $2 \mathrm{n}$ DNA, and $S / G_{2} / M$-representing cells with DNA content $>2 \mathrm{n}[35,36]$.

2.11. Cell Viability and Apoptosis. Apoptotic cells were identified and quantified by flow cytometry using the Annexin V-FITC/PI Apoptosis Detection kit (BD Bioscience) according to the manufacturer's instruction. Briefly, $10^{6}$ blood cells were resuspended in binding buffer and incubated for $15 \mathrm{~min}$ at room temperature, in the dark, with $5 \mu \mathrm{L}$ annexin V-FITC and $5 \mu \mathrm{L}$ propidium iodide (PI). Data were
TABLE 1: Patient characteristics.

\begin{tabular}{lccc}
\hline Parameters & $\begin{array}{c}\text { Women } \\
(n=11)\end{array}$ & $\begin{array}{c}\text { Men } \\
(n=2)\end{array}$ & $p$ value \\
\hline Age (years) & $78.7 \pm 3$ & $78 \pm 7$ & 0.93 \\
BMI $\left(\mathrm{kg} / \mathrm{m}^{2}\right)$ & $25.8 \pm 0.6$ & $27 \pm 1.7$ & 0.61 \\
Education level (years) & $5.9 \pm 0.6$ & $5 \pm 1.0$ & 0.51 \\
Treatment duration (years) & $1.85 \pm 0.7$ & $0.6 \pm 0.1$ & 0.08 \\
\hline
\end{tabular}

*The values are presented as mean \pm SD.

acquired using the FACSCanto II flow cytometer (BD) and analyzed by the FCS Express software (De Novo). Doublenegative cells were considered viable, while annexin VFITC-positive cells were considered apoptotic [27, 35, 36]. Data are expressed as percentage of cells.

2.12. Statistical Analysis. All data are expressed as the mean \pm SEM (except for the characteristics of patients, expressed as means \pm SD). The Kolmogorov-Smirnov test was applied to assess the normal distribution of data. Considering that all the samples had Gaussian distribution, Student's $t$-test for paired samples was used for the statistical analysis of cytokine concentration, ROS, apoptosis indexes, and cell viability before and after the administration of probiotic. $p$ values $<0.05$ were considered statistically significant. Statistical analysis was performed using the GraphPad Prism software, version 7.0.

\section{Results}

3.1. Characteristics of Patients (Demographic, Anthropometric, and Social Characteristics). Table 1 shows the clinical characteristics of elderly patients included in this study. No significant differences between gender groups were observed in relation to age, body mass index (BMI), treatment duration, and education level.

3.2. Cognitive Assessment. Figure 2 summarizes the results of the cognitive tests divided into T0 and T90 time points. We observed an improvement of performance in the MMSE in 28\% (T0: $17.4 \pm 1.03$ hits and T90: $22.3 \pm 0.82$ hits, $p<0.0001$ ), indicating the benefits of kefir-fermented milk on "global cognitive status" (Figure 2(a)). A similar impact was observed on "memory analysis" (Figure 2(b), left panel) through the immediate memory test $(\sim 66 \%, p<0.05)$ and late memory test $(\sim 62 \%, p<0.05)$ between T0 and T90. In the center of Figure 2(b), we also demonstrate the improvement of "visual-spatial and abstraction abilities" using the Similarity Test $(\sim 2$-fold increase, $p<0.05)$ and Cookie Theft Picture Test ( 2-fold increase, $p<0.05)$. Concerning the "executive and language functions" (Figure 2(b), right panel), we also note a significant increment through the Boston Test $(\sim 30 \%, p<0.05)$ and verbal fluency test $(\sim 25 \%, p<0.05)$. Finally, the "cognitive battery assay" showed a significant amelioration on the constructive abilities, evidenced by the improvement on the clock-drawing test (T0: $9.0 \pm 2.4$ hits and T90: $13.2 \pm 2.3$ hits, 


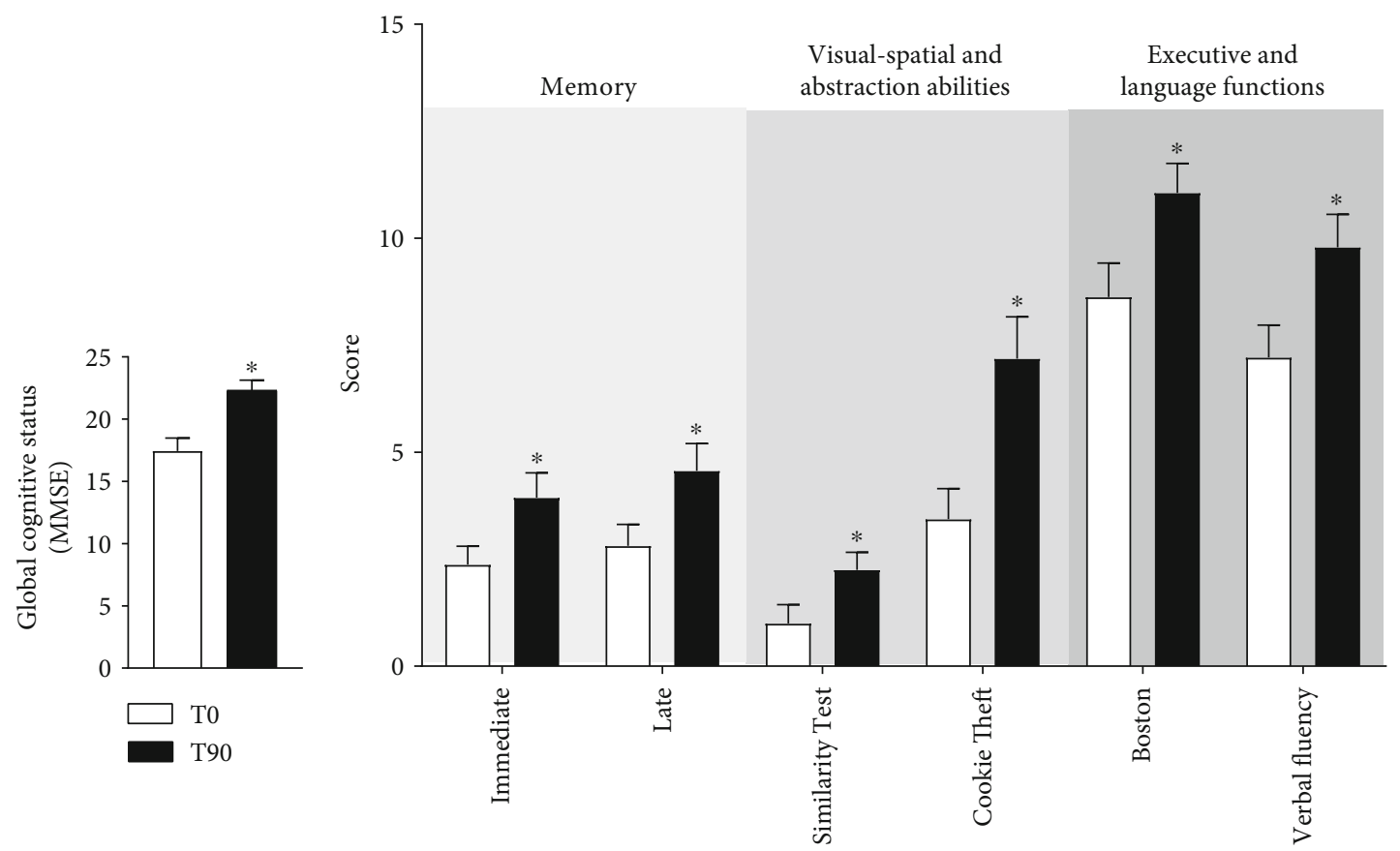

(a)

(b)

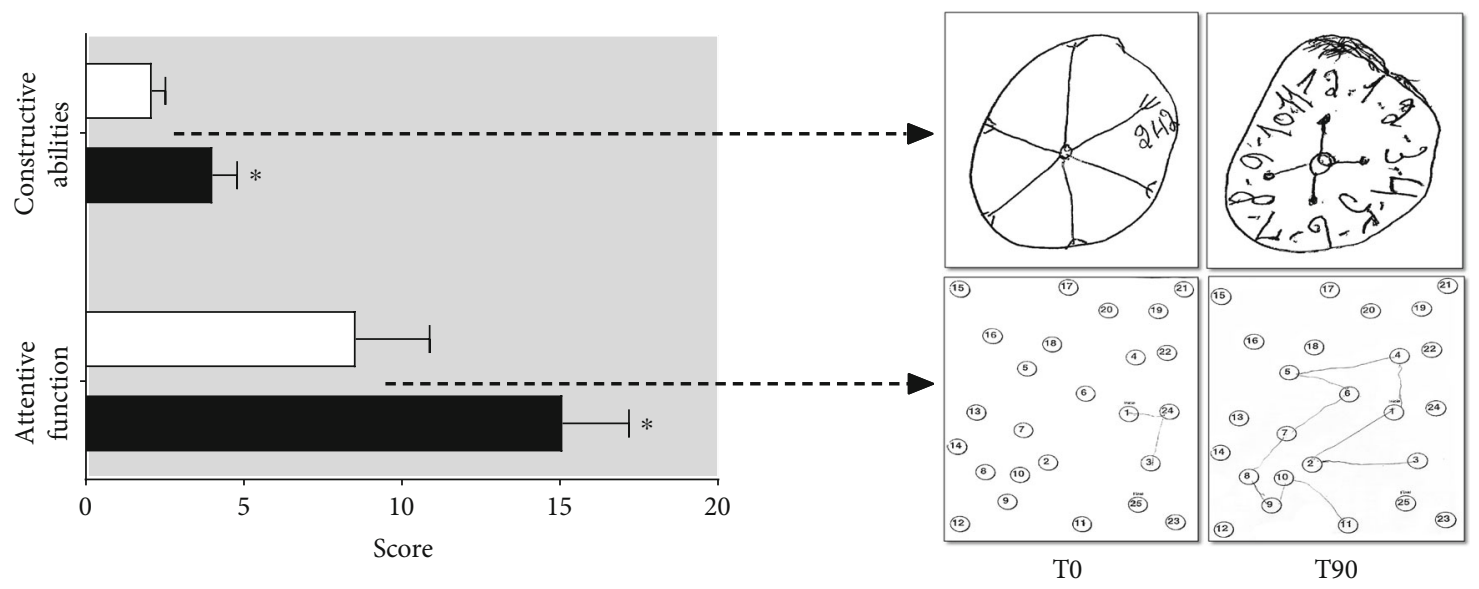

(c)

FIGURE 2: Series of panels showing the results of the evaluation of cognitive tests before and after treatment using kefir (a fermented milk with synbiotics). (a) Global cognitive status (by Mini-Mental State Examination (MMSE)) comparing the effect of the treatment with the previous observed values. (b) Memory analysis (by immediate and late tests, left panel), visual-spatial and abstraction abilities (by Similarity Test and Cookie Theft Picture Test, center panel), and executive and language functions (by Boston Naming Test and verbal fluency test, right panel). (c) Cognitive battery assay, evaluated through constructive abilities and attentive function, with typical hand drawings of the patients during the applied test. The results are expressed as mean \pm SEM $(n=13) .{ }^{*} p<0.05$ compared to T0.

$p<0.05)$, and on attentive function testified by the Trail Making Test $(40 \%, p<0.05)$.

3.3. Cytokines. Figure 3 shows the quantification of some cytokines involved in pathogenesis of neurodegenerative diseases. The levels of proinflammatory cytokines TNF- $\alpha$, IL-8, and IL12p70 were lower at T90 than at T0 $(\sim 1.5$-fold decrease, respectively). However, other proinflammatory (such as IL-1b and IL-6) or anti-inflammatory (IL-10) cytokines did not show difference between T90 and T0. Interestingly, analyzing the balance between proinflammatory and anti-inflammatory cytokines (Figure $3(\mathrm{~g})$ ), we verified that the probiotic supplementation was able to reduce the IL8/IL-10 and IL-12/IL-10 ratios (T0: $2.3 \pm 0.2$ vs. T90: $1.7 \pm$ $0.1 \mathrm{pg} / \mathrm{mL}$ and T0 : $0.95 \pm 0.05$ vs. T90: $0.72 \pm 0.08 \mathrm{pg} / \mathrm{mL}$, respectively, $p<0.05$ ).

3.4. Direct and Indirect Oxidative Stress Biomarkers. Oxidative stress was evaluated by flow cytometry trough DHE, DCF, HPF, and DAF fluorescence. Figure 4 shows systemic ROS production measured before and after kefir treatment. We observed a significant decrease in serum levels of $\mathrm{O}_{2}{ }^{-}$, $\mathrm{H}_{2} \mathrm{O}_{2}$, and $\mathrm{ONOO}^{-} / \mathrm{OH}^{-}$(Figure 4(a)) with a simultaneous increase in NO levels (Figure 4(b)). The bar graph in 


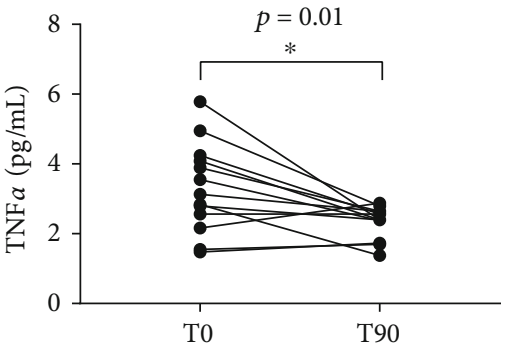

(a)



(d)

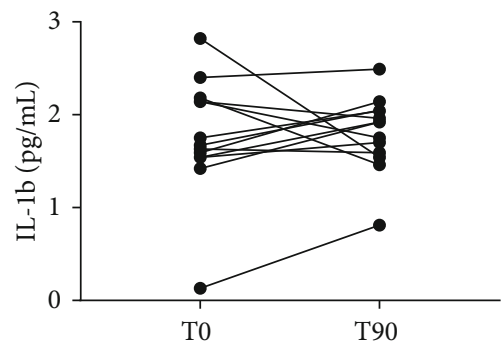

(b)

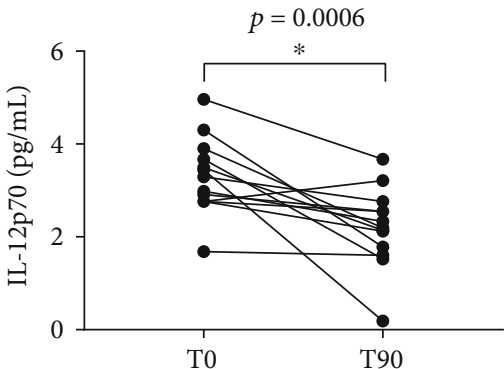

(e)

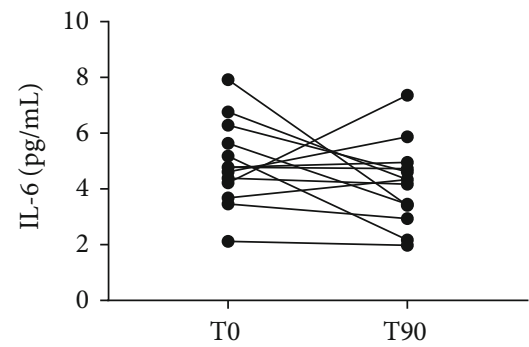

(c)

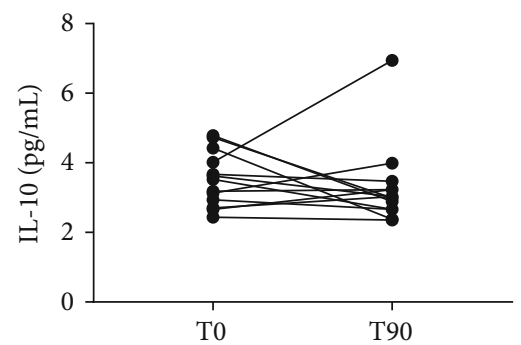

(f)

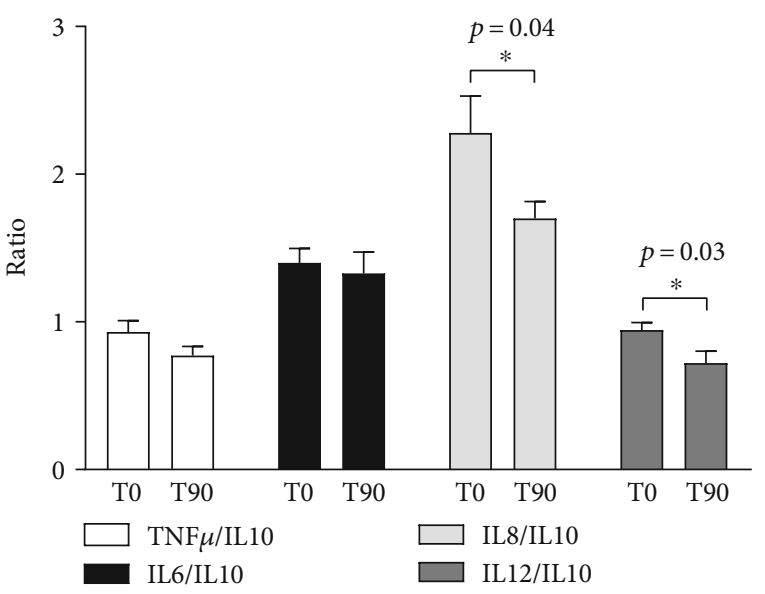

(g)

FIgURe 3: Cytokine levels measured by the Cytometric Bead Array (CBA) using protocols performed through flow cytometry analysis. TNF- $\alpha$ (a), IL-1b (b), IL-6 (c), IL-8 (d), IL-12p70 (e), IL-10 (f), and the ratio of proinflammatory/anti-inflammatory markers (g) were measured before and after probiotic supplementation. The results are expressed as mean \pm SEM $(n=13) .{ }^{*} p<0.05$ compared to T0.

Figure 4(c) represents the mean values of systemic $\mathrm{O}_{2}{ }^{-}$(T0: $5953 \pm 999$ vs. T90: $3622 \pm 707$, a.u.), $\mathrm{H}_{2} \mathrm{O}_{2}$ (T0: $4580 \pm 611$ vs. T90: $3202 \pm 286$, a.u.), $\mathrm{ONOO}^{-} / \mathrm{OH}^{-}$(T0: $1161 \pm 70$ vs. T90: $874 \pm 34$, a.u.), and NO (T0: $3493 \pm 304$ vs. T90: 1799 \pm 158 ) between $\mathrm{T} 0$ and $\mathrm{T} 90$.

Figure 5 shows the assessment of systemic protein oxidation by AOPP (an important indirect biomarker of oxidative stress). The results revealed that kefir administration leads to a remarkable decrease in protein oxidation (T0: $8.4 \pm 0.6$ vs. T90: $2.9 \pm 0.3 \mu \mathrm{mol} / \mathrm{mg}$ ).

3.5. Mitochondrial Membrane Potential (MMP). We further evaluated whether the decrease in ROS production was accompanied by a recovery of mitochondrial membrane potential (MMP) due to kefir administration. The level of membrane polarization after kefir treatment is shown in Figure 6(a) (left panel). JC-10 green fluorescence (reflecting mitochondrial dysfunction) significantly decreased, and JC10 red fluorescence (reflecting mitochondrial integrity) increased after kefir consumption. Most of the cells shifted towards the red fluorescence after kefir consumption indicating a significant preservation of mitochondrial function (T0: $0.11 \pm 0.03$ vs. T90: $2.0 \pm 0.14$, FL2/FL1, a.u.).

3.6. p53 Expression. The protein p53 is a transcription factor that plays an important role in maintaining the genome integrity by controlling cell apoptosis and cell cycle arrest through signaling of genotoxic stress, like oxidative stress. Figure 6(a) (right panel) shows the values of p53 expression levels measured in the blood samples before and after kefir 




(a)

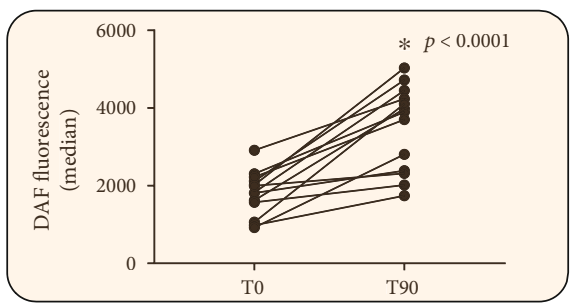

(b)

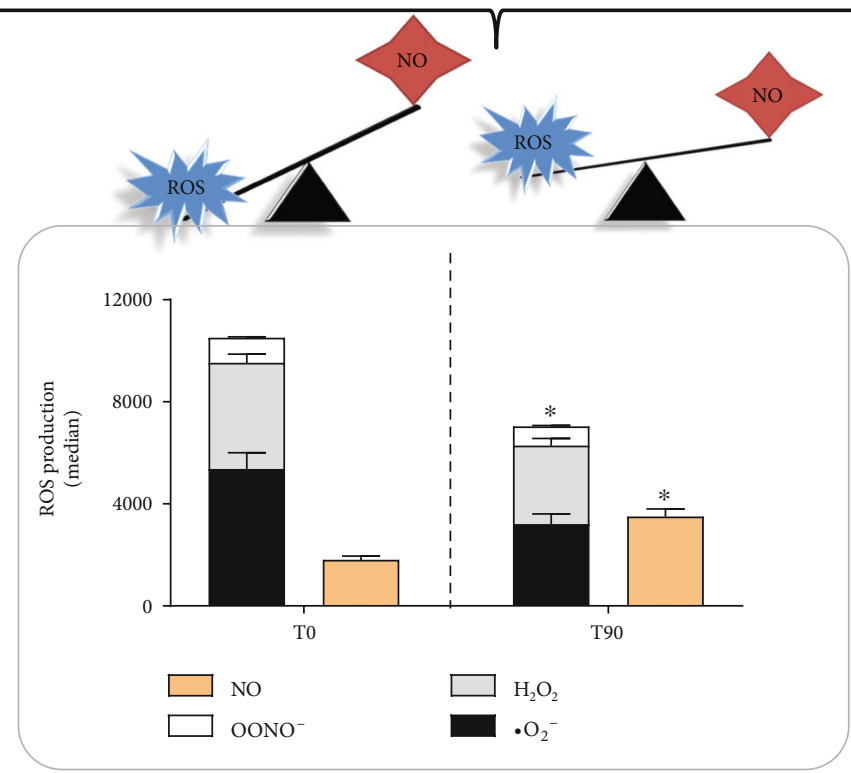

(c)

FIGURE 4: Superoxide anion, hydrogen peroxide, peroxynitrite/hydroxyl radical, and nitric oxide levels measured by specific biomarkers commonly used to evaluate ROS (DHE, DCF, HPF, and DAF staining, respectively). Records of ROS production were made before and after 90 days of the probiotic supplementation. Note a marked recovery of the ROS imbalance after the treatment. The results were expressed as mean \pm SEM $(n=13) .{ }^{*} p<0.05$ compared to T0.

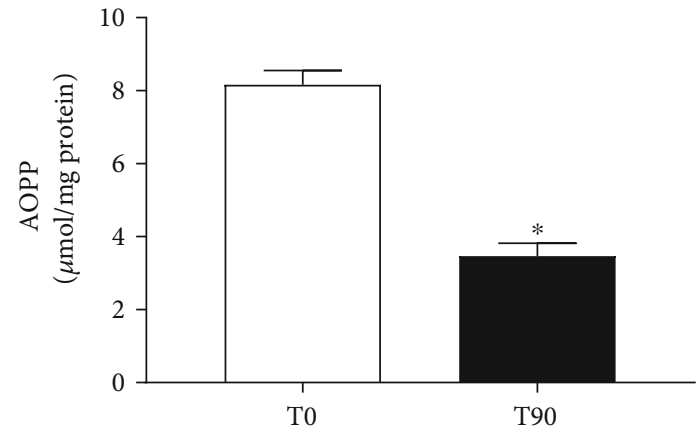

FIGURE 5: Levels of advanced oxidative protein products before and after probiotic supplementation. The results are expressed as mean $\pm \operatorname{SEM}(n=13) .{ }^{*} p<0.05$ compared to T0. treatment. As shown, p53 expression increased from T0 $(10.1 \pm 1.8 \%)$ to $\mathrm{T} 90(29.6 \pm 2.9 \%)$.

3.7. Cell Cycle Arrest. Cell cycle distribution was determined using flow cytometric analysis of blood cells. As shown in Figure 6(b) (left panel), kefir consumption induced an increase in the $G_{0} / G_{1}$ phase, indicating a cell cycle arrest in T90 in comparison to T0 (T0: $61 \pm 3.7$ vs. T90: $92 \pm 1.0 \%$ ). Simultaneously, we observed a decrease in the percentage of cells in $S / G_{2} / M$ phases of the cell cycle after kefir consumption (data not shown).

3.8. DNA Fragmentation. Results showed a significant decrease in cells with sub- $\mathrm{G}_{0}$ DNA content after kefir treatment. A DNA fragmentation assay was performed to 

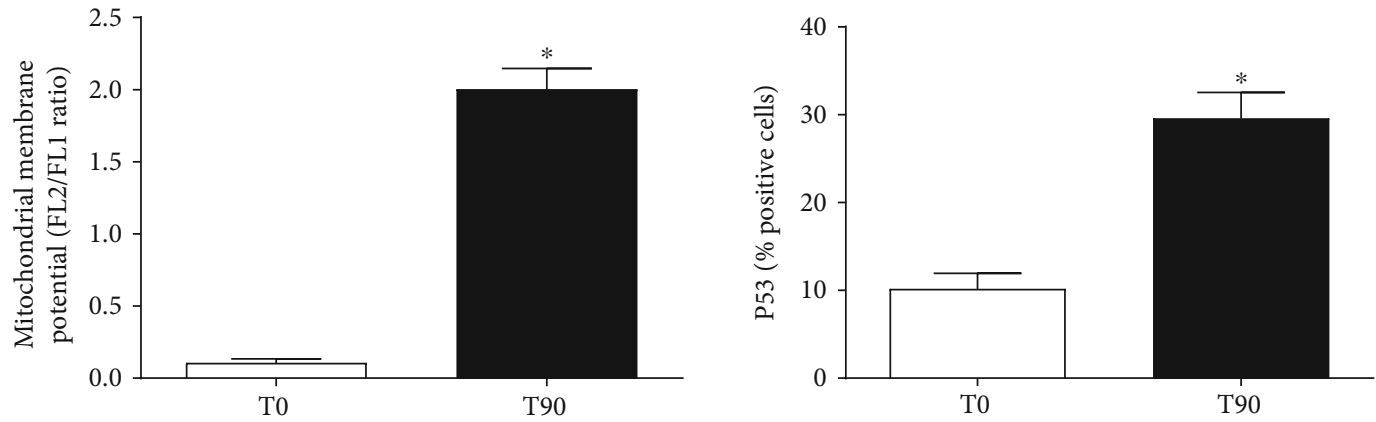

(a)
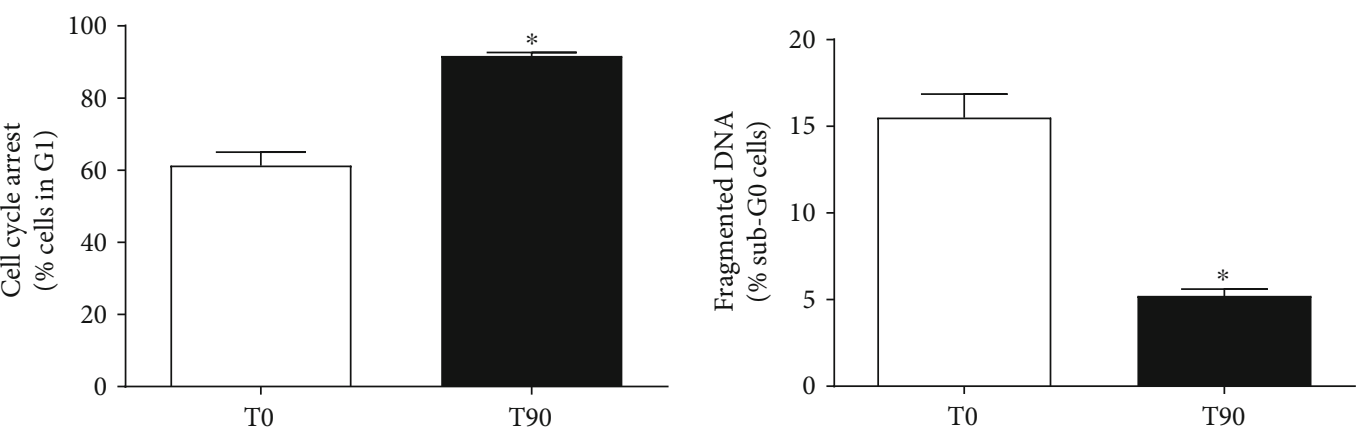

(b)
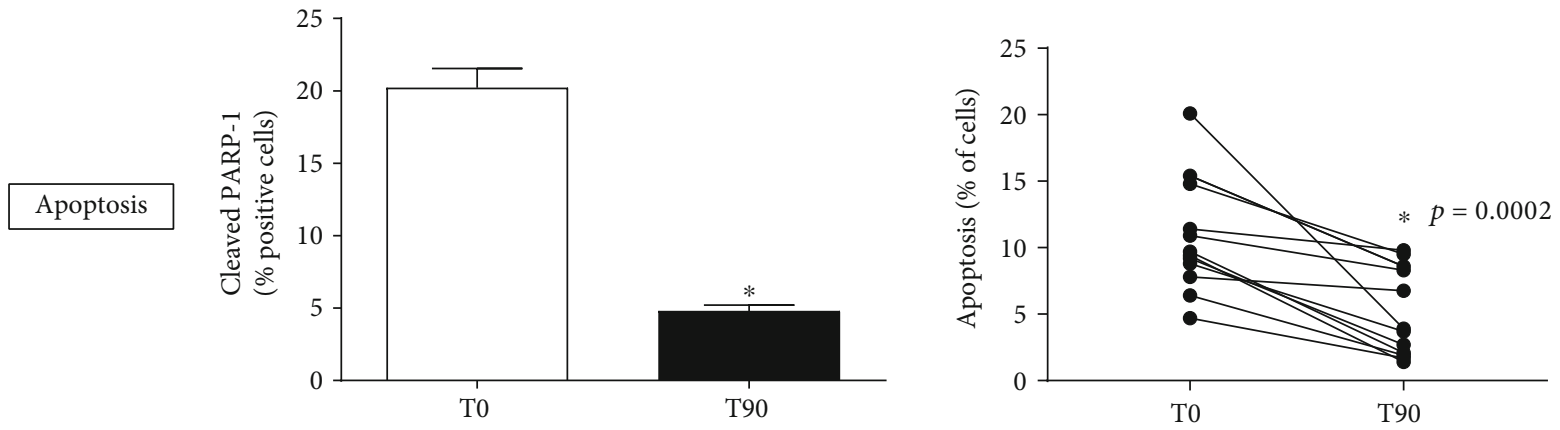

(c)

FIGURE 6: Different evidences that kefir supplementation protects against cellular damage. The mitochondrial membrane potential (MMP) and p53 expression (a), followed by induced cell cycle arrest and DNA repair (b), accompanied by a marked decrease in apoptosis (c). The results are expressed as mean $\pm \operatorname{SEM}(n=13) .{ }^{*} p<0.05$ compared to T0.

determine whether kefir was capable of protecting DNA from damage in cells undergoing increased ROS production. As shown in Figure 6(b) (right panel), kefir administration was able to reduce DNA fragmentation from $15.5 \pm 1.3 \%$ in T0 to $5.2 \pm 0.4 \%$ in T90. This finding suggests significant changes in cell cycle progression and induction of apoptosis.

3.9. Cleavage of PARP-1. Poly (ADP-ribose) polymerase 1 (PARP-1) is involved in several biological processes, such as cell cycle progression, DNA repair and regulation of transcription, and programmed cell death. Proteolytic cleavage of PARP is considered a hallmark of apoptosis, since PARP-1 is cleaved by activated apoptotic caspases. Our flow cytometry analysis showed a significant reduction in the percentage of cleaved PARP-1 after kefir consumption (T0: $20.2 \pm 1.3$ vs. T90: $4.8 \pm 0.4 \%$ ) (Figure 6(c), left panel).
3.10. Apoptosis Assay. Flow cytometry was used to determine the antiapoptotic effect of kefir by quantification of annexin V-positive cells. Phosphatidylserine (PS) is externalized and available for detection by annexin $\mathrm{V}$ when cells undergo apoptosis. After kefir treatment, the percentage of annexin V-positive cells decreased in T90 (6.86 $\pm 1.91 \%)$ compared to T0 $(12.88 \pm 1.91 \%)$ (Figure 6(c), right panel); consequently, majority of cells were negative for annexin $\mathrm{V}$ indicating their healthy status. The viable-to-apoptotic cell ratio (V/A ratio) was 2.05 , and the mean V/A ratio increased from 6.53 at $\mathrm{T} 0$ to 13.39 at $\mathrm{T} 90$.

\section{Discussion}

In 1908, a Russian zoologist named Metchnikoff (the Nobel laureate who discovered phagocytosis) popularized for the 
first time the consumption of probiotics in the form of yogurt as a "healthy food" [39-41]. However, only 100 years later, it has been recognized that probiotics may influence CNS function via the microbiota-gut-brain axis [19, 42, 43]. Even so, clinical investigations using probiotics in elderly patients with dementia are still scarce in medical literature [15]. In this context, our study is the first to evaluate the beneficial effects of kefir supplementation (at the minimum dose of $2 \mathrm{~mL} / \mathrm{kg}$ for 90 days) on cognitive function, biomarkers of systemic oxidative stress, inflammation, and cell damage in elderly patients with AD.

Although it is known that $\mathrm{AD}$ patients are susceptible to multiple complications related to cognitive performance, the innovative therapeutic strategies to reverse this progression are still scant. Interestingly, our results with kefir supplementation for 3 months improved all cognitive tests applied in our experiment (memory, visual-spatial function and abstraction abilities, executive and language functions, constructive abilities, and attentive function). Our results corroborate the findings of Akbari et al. [19] that also demonstrated that probiotic milk (containing Lactobacillus acidophilus, Lactobacillus casei, Bifidobacterium bifidum, and Lactobacillus fermentum) for 12 weeks are able to improve the cognitive function. More recently, Kobayashi et al. [44] reported that oral 24-week supplementation with Bifidobacterium breve A1 improved cognitive function in $\mathrm{AD}$ patients. As suggested by others, we speculated that kefir supplementation also could alter the gut microbiota contributing to neuromodulation through neuroactive and neuroendocrine synthesis (e.g., acetylcholine, dopamine, serotonin, norepinephrine, adrenaline, glutamate, gammaaminobutyric acid, and brain-derived neurotrophic factor (BDNF)) besides their related receptor expression $[15,19$, 45-49]. This hypothesis is partially based on early findings in $\mathrm{AD}$ patients using multispecies probiotic intake (for 1 month) improving gut bacteria composition and serum tryptophan levels, an amino acid precursor in serotonin and melatonin biosynthesis [50]. Moreover, experimental evidences support this idea demonstrating decreased level of serum serotonin, BDNF, and NMDA receptors in germ-free mice compared to conventional mice $[19,51$, 52] and that Lactobacilli supplementation can increase GABA availability from glutamate [53]. More recently, another data demonstrated in mice revealed that the gut microbiota is a potent influencer of BDNF in cortical and hippocampal areas, besides increasing striatal monoamine turnover and modulating the expression of serotonin receptor $1 \mathrm{~A}[48,54]$. Despite all these neuromodulatory benefits previously described, it is believed that the influence on inflammation and oxidative stress by probiotics may also contribute to the neuroprotective effect, thus justifying the next step of this study.

Neuroinflammation has been observed as another relevant player in $\mathrm{AD}$ pathogenesis in both experimental and clinical studies [11, 12, 55-59]. Numerous data demonstrate positive associations between proinflammatory cytokines (e.g., IL-1, IL-6, TNF- $\alpha$, IL-8, and IL-12) and the progression of $\mathrm{AD}[58,60]$. Moreover, recent investigations reported that these neuroinflammatory cytokines can compromise the clearance of $\mathrm{A} \beta$, accumulating this toxic protein in the brain $[57,58,61-63]$. Thus, cytokine balance has been an important research target for understanding the pathophysiology of $\mathrm{AD}$ and identifying new potential therapeutic targets. At the same time, emerging data have shown that probiotics can secrete metabolites and factors with immunomodulatory properties [24, 48, 64]. For example, relevant studies demonstrated a decrease in proinflammatory cytokines using multistrain probiotic supplementation $[21,65,66]$. The novelty in our study was that we used an inexpensive food (and easily produced at home) to reduce serum proinflammatory cytokines and possibly contribute to neuroprotective effect in $\mathrm{AD}$ patients. This immunosuppressive profile is reinforced by other recent study from our lab using only nonbacterial fraction of kefir in dyslipidemic mice [30], which allows us to speculate that this immunomodulation could be the result of a synergistic effect between microorganisms and soluble products present in kefir.

Increased levels of serum oxidative stress biomarkers reported in neurodegenerative diseases [11, 19, 67-71] seem to be an interesting approach to evaluate the impact of new therapeutic strategies in $\mathrm{AD}$ patients. At the same time, there is a strong correlation of antioxidant-rich diets as an "easy" strategy for neuroprotection $[11,17,72,73]$, including probiotics $[19,21]$. In this study, the assessment of serum oxidative stress by direct and indirect methods (ROS and AOPP) demonstrates that kefir has significant antioxidant effects, helping to explain the favorable result concerning cognition in $\mathrm{AD}$ patients. It is known that excessive ROS are involved as a cause and consequence of proinflammation contributing directly and indirectly to the pathogenesis of $\mathrm{AD}[8,17,74-76]$. More specifically, due to their electronegativity and reactivity, $\mathrm{O}_{2}^{-}, \mathrm{H}_{2} \mathrm{O}_{2}$, and $\mathrm{ONOO}^{-} / \mathrm{OH}^{-}$can oxidize lipids, nucleic acids, and proteins leading to mitochondrial destruction, neuroexcitotoxicity (e.g., excessive $\mathrm{Ca}^{2+}$ influx and formation of aggregates of toxic proteins), and stimulation of microglia and astrocytes to develop inflammatory response $[17,24,36,77]$. On the other hand, NO (by eNOS or nNOS isoforms) seems to be a "ROSgasotransmitter" with important neuroprotective properties such as antioxidant (acting as a scavenger of $\mathrm{O}_{2}{ }^{-}$), vasodilator (increasing cerebral blood supply to neurons), inhibitor of NMDA receptors at glutamatergic synapses (thereby preventing neuroexcitotoxicity), and preventing the deposition of $\mathrm{A} \beta[10,78-81]$. Interestingly, our findings demonstrate for the first time that kefir reduces serum ROS bioavailability accompanied by an NO increase reflecting the reduction of plasma protein oxidation in AD patients. These data may be supported by experiments of Musa et al. [21] that revealed an increase in the activity of antioxidant enzymes (SOD, GSH, and GPx) in the brain tissue of mice treated with Lactobacillus. Therefore, all these results motivated us to investigate the impact of mitochondrial and cell damage obtained by the same blood samples from the same subjects.

It is known that $\mathrm{AD}$ brain mitochondria develop diminished membrane potential, disrupting the electron transfer chain, favoring excess ROS production, alteration in cytosolic calcium homeostasis, and $\mathrm{A} \beta$ accumulation leading to neurodegeneration $[11,72,82-85]$. In parallel, 


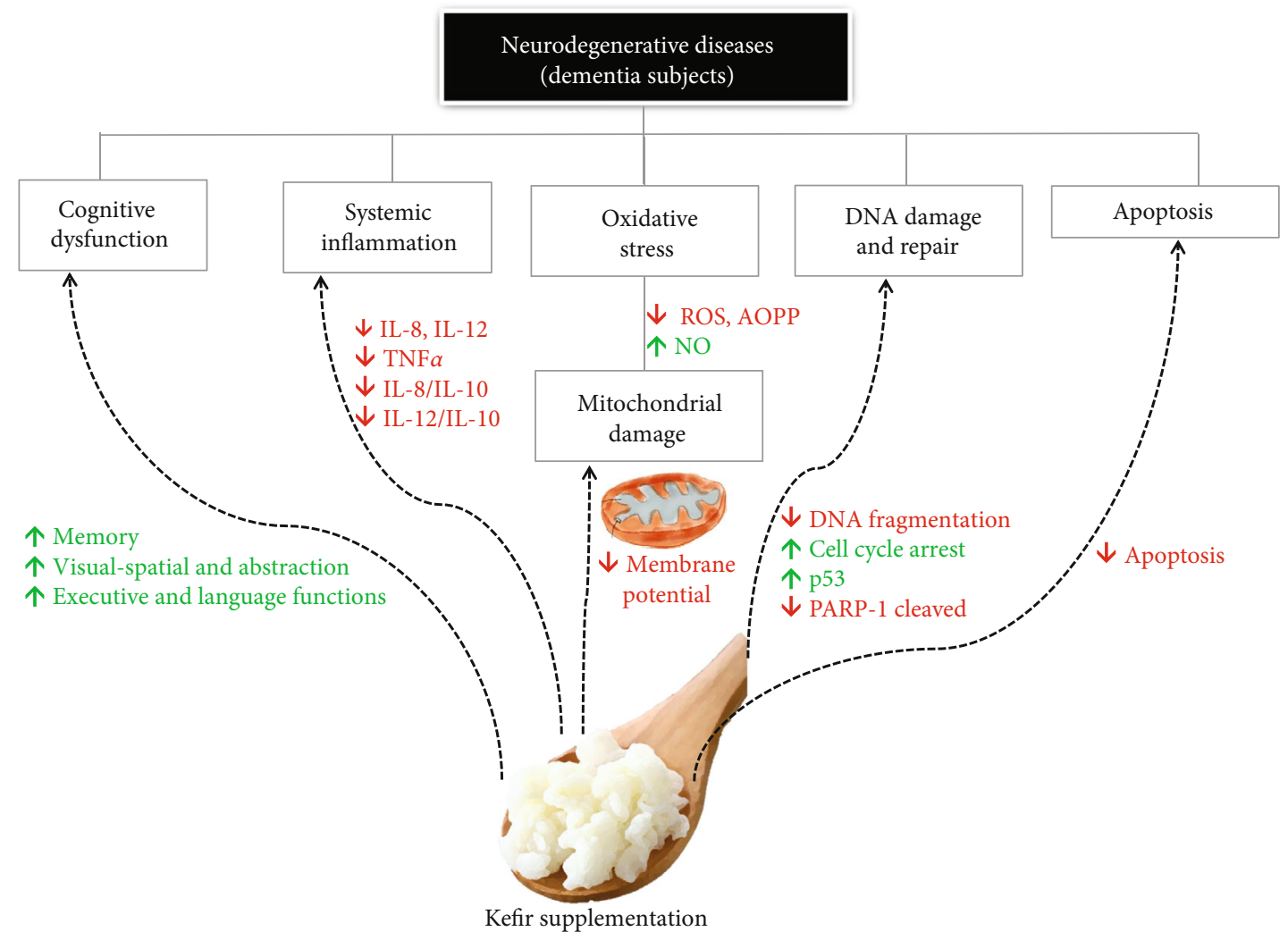

Figure 7: Beneficial effects of kefir on dementia in AD patients. Simplified scheme of main effects after 90 days with kefir supplementation on Alzheimer's subjects.

Delbarba et al. [86] demonstrated that mitochondrial DNA can decrease in peripheral blood in the early stages of neurodegenerative disease progression, being a potential "bloodbased signature" in AD patients. Therefore, since several studies of mitochondrial damage in Alzheimer's patients are performed postmortem, the possibility of exploring blood samples in clinical investigations (as in the present study) may be a promising strategy for establishing mechanisms related to cognitive improvement with immunomodulatory, antioxidant, and/or mitochondrial function. Interestingly, we observed that kefir was able to reverse the compromised mitochondrial membrane potential in blood cells of $\mathrm{AD}$ patients, helping to explain (at least in part) the reduction of ROS bioavailability in the same patients. Furthermore, in this same context, as it is known that p53 under lower ROS levels can contribute to cellular survival [87-89], we confirmed this protective effect by kefir in $\mathrm{AD}$ patients through 2 evidences: (1) by induction of DNA repair and (2) by reduction of apoptosis. Firstly, we may affirm this beneficial effect through a decrease in DNA fragmentation accompanied by induction of cell cycle arrest after 90 days of supplementation. Secondly, the reduction of apoptosis by kefir was detected through a reduction of cleaved PARP-1 (considered to be a classical hallmark of apoptosis) and by a decrease in annexin $\mathrm{V}$-positive cells $[36,90]$. In summary, our data indicate that kefir supplementation has also a mitochondria-protective effect in addition to cytoprotective and antiapoptotic action, whose effects try to mitigate the progression of neurodegeneration (Figure 7).
This study had some potential methodological limitations. First, due to difficulties in obtaining fresh fecal samples, we had problems with analysis of the fecal microbiota before and after the kefir supplementation in our AD patients. Second, our study was conducted without control participants using other type of fermented milk. Third, the sample size was small, but justified by age of the patients, and it was accompanied by severe exclusion criteria. Additionally, the impact of learning effect bias was minimized through randomized procedures applied in the cognitive tests in the present study. Lastly, but not least, we could have enriched the data exploring imaging biomarkers (e.g., magnetic resonance imaging and PET) or specific biomarkers (e.g., brain-derived neurotrophic factor, neuronal butyrylcholinesterase, and apolipoprotein A1) which would extend the possible beneficial effects induced by chronic kefir administration in these $\mathrm{AD}$ patients. Despite these limitations, the novelty of our study is to demonstrate the beneficial effects of chronic kefir supplementation on the cognitive function in the elderly with AD.

\section{Conclusion}

The current study demonstrated that synbiotic supplementation for 90 days to older patients with $\mathrm{AD}$ had reparatory favorable effects on cognitive dysfunction (improving memory, language, executive functions, visual-spatial function, conceptualization, and abstraction abilities), systemic inflammation (by reduction of proinflammatory 
cytokines), systemic oxidative stress (verified by a decrease in ROS and AOPP), and blood cell damage (analyzed by DNA damage/repairment and apoptosis). Therefore, the data of the present study is opening a great opportunity for the evaluation of the clinical benefits of probiotics/synbiotics at larger randomized controlled clinical trials, strengthening the present valuable findings.

$\begin{array}{ll}\text { Abbreviations } \\ \text { DA: } & \text { Alzheimer's disease } \\ \text { CNS: } & \text { Central nervous system } \\ \text { ROS: } & \text { Reactive oxygen species } \\ \text { MMSE: } & \text { Mini-Mental State Examination } \\ \text { CBA: } & \text { Cytometric Bead Array } \\ \text { MFI: } & \text { Median fluorescence intensity } \\ \text { DHE: } & \text { Dihydroethidine } \\ \text { DCF: } & \text { Dichlorofluorescein } \\ \text { HPF: } & \text { Hydroxyphenyl fluorescein } \\ \text { DAF: } & \text { Diaminofluorescein } \\ \text { AOPP: } & \text { Advanced oxidation protein products } \\ \text { MMP: } & \text { Mitochondrial membrane potential } \\ \text { CCCP: } & \text { Carbonyl cyanide 3-chlorophenyl-hydrazone } \\ \text { PI: } & \text { Propidium iodide } \\ \text { BMI: } & \text { Body mass index } \\ \text { PARP-1: } & \text { Poly (ADP-ribose) polymerase 1 } \\ \text { PS: } & \text { Phosphatidylserine } \\ \text { V/A ratio: } & \text { Viable-to-apoptotic cell ratio } \\ \text { BDNF: } & \text { Brain-derived neurotrophic factor } \\ \text { SEM: } & \text { Standard error of the mean } \\ \text { UVV: } & \text { Vila Velha University. } \\ & \end{array}$

\section{Data Availability}

All data used to support the findings of this study are included within the article.

\section{Ethical Approval}

All subjects and their tutors were fully educated on the nature of the project. The research was approved by the ethics committee of Vila Velha University (\#1.804.392).

\section{Consent}

All subjects and their tutors signed the free informed consent form.

\section{Conflicts of Interest}

The authors declare that the research was conducted in the absence of any commercial or financial relationships that could be construed as a potential conflict of interest.

\section{Authors' Contributions}

ECV, AMMT, BPC, CMA, and SSM conceived and designed the study. AMMT, BPC, GAA, RA, LZC, and CMA conducted the clinical research and the laboratory tests. AMMT, BPC, MCT, ECV, and TMCP analyzed the data and drafted the manuscript. All authors approved the final version of the manuscript.

\section{Acknowledgments}

We are grateful to LADEPAF-Clinical Analysis Laboratory for providing the kits for biological sample collection and Tommasi Analysis Laboratory for letting us use their facilities. This study was supported by the National Council for Scientific and Technological Development (CNPq) and the State Agency for the Development of Science and Technology (FAPES) through the Edital 24/2018 -PRONEx \#84321148, TO 569/2018.

\section{References}

[1] J. C. Beck, D. F. Benson, A. B. Scheibel, J. E. Spar, and L. Z. Rubenstein, "Dementia in the elderly: the silent epidemic," Annals of Internal Medecine, vol. 97, no. 2, pp. 231-241, 1982.

[2] S. Duong, T. Patel, and F. Chang, "Dementia: what pharmacists need to know," Canadian Pharmacists Journal, vol. 150, no. 2, pp. 118-129, 2017.

[3] C. Brayne and B. Miller, "Dementia and aging populations - a global priority for contextualized research and health policy," PLOS Medicine, vol. 14, no. 3, p. e1002275, 2017.

[4] C. Bastin, E. Delhaye, C. Moulin, and E. J. Barbeau, "Novelty processing and memory impairment in Alzheimer's disease: a review," Neuroscience \& Biobehavioral Reviews, vol. 100, pp. 237-249, 2019.

[5] GBD 2016 Dementia Collaborators, "Global, regional, and national burden of Alzheimer's disease and other dementias, 1990-2016: a systematic analysis for the Global Burden of Disease Study 2016," Lancet Neurology, vol. 18, no. 1, pp. 88-106, 2019.

[6] G. C. Román and F. Boller, "Vascular factors in neurodegenerative diseases: a path towards treatment and prevention," Functional Neurology, vol. 29, 2014.

[7] R. León and J. Marco-Contelles, "A step further towards multitarget drugs for Alzheimer and neuronal vascular diseases: targeting the cholinergic system, amyloid- $\beta$ aggregation and $\mathrm{Ca} 2++$ dyshomeostasis," Current Medicinal Chemistry, vol. 18, no. 4, pp. 552-576, 2011.

[8] G. Benzi and A. Moretti, "Are reactive oxygen species involved in Alzheimer's disease?," Neurobiology of Aging, vol. 16, no. 4, pp. 661-674, 1995.

[9] Z. Liu, T. Li, P. Li et al., "The ambiguous relationship of oxidative stress, tau hyperphosphorylation, and autophagy dysfunction in Alzheimer's disease," Oxidative Medicine and Cellular Longevity, vol. 2015, Article ID 352723, 12 pages, 2015.

[10] R. Balez and L. Ooi, "Getting to NO Alzheimer's disease: neuroprotection versus neurotoxicity mediated by nitric oxide," Oxidative Medicine and Cellular Longevity, vol. 2016, Article ID 3806157, 8 pages, 2016.

[11] T. Jayasena, A. Poljak, N. Braidy et al., "Upregulation of glycolytic enzymes, mitochondrial dysfunction and increased cytotoxicity in glial cells treated with Alzheimer's disease plasma," PLoS One, vol. 10, no. 3, p. e0116092, 2015.

[12] M. Bostancıklığlu, "An update on the interactions between Alzheimer's disease, autophagy and inflammation," Gene, vol. 705, pp. 157-166, 2019. 
[13] A. M. Kubis-Kubiak, A. Rorbach-Dolata, and A. Piwowar, "Crucial players in Alzheimer's disease and diabetes mellitus: friends or foes?," Mechanisms of Ageing and Development, vol. 181, pp. 7-21, 2019.

[14] S. S. Rao and P. A. Adlard, "Untangling tau and iron: exploring the interaction between iron and tau in neurodegeneration," Frontiers in Molecular Neuroscience, vol. 11, no. 276, 2018.

[15] K. Kowalski and A. Mulak, "Brain-gut-microbiota axis in Alzheimer's disease," Journal of Neurogastroenterology and Motility, vol. 25, no. 1, pp. 48-60, 2019.

[16] F. Massoud and S. Gauthier, "Update on the pharmacological treatment of Alzheimer's disease," Current Neuropharmacology, vol. 8, no. 1, pp. 69-80, 2010.

[17] D. M. A. Oliver and P. H. Reddy, "Small molecules as therapeutic drugs for Alzheimer's disease," Molecular and Cellular Neuroscience, vol. 96, pp. 47-62, 2019.

[18] B. J. Balin and A. P. Hudson, "Etiology and pathogenesis of late-onset Alzheimer's disease," Current Allergy and Asthma Reports, vol. 14, no. 3, p. 417, 2014.

[19] E. Akbari, Z. Asemi, R. Daneshvar Kakhaki et al., "Effect of probiotic supplementation on cognitive function and metabolic status in Alzheimer's disease: a randomized, double-blind and controlled trial," Frontiers in Aging Neuroscience, vol. 8, no. 256, pp. 1-8, 2016.

[20] E. C. Vasquez, T. M. C. Pereira, V. A. Peotta, M. P. Baldo, and M. Campos-Toimil, "Probiotics as beneficial dietary supplements to prevent and treat cardiovascular diseases: uncovering their impact on oxidative stress," Oxidative Medicine and Cellular Longevity, vol. 2019, 11 pages, 2019.

[21] N. H. Musa, V. Mani, S. M. Lim, S. Vidyadaran, A. B. Abdul Majeed, and K. Ramasamy, "Lactobacilli-fermented cow's milk attenuated lipopolysaccharide-induced neuroinflammation and memory impairment in vitro and in vivo," Journal of Dairy Research, vol. 84, no. 4, pp. 488-495, 2017.

[22] A. M. de Oliveira Leite, M. A. L. Miguel, R. S. Peixoto, A. S. Rosado, J. T. Silva, and V. M. F. Paschoalin, "Microbiological, technological and therapeutic properties of kefir: a natural probiotic beverage," Brazilian Journal of Microbiology, vol. 44, no. 2, pp. 341-349, 2013.

[23] A. G. F. Friques, C. M. Arpini, I. C. Kalil et al., "Chronic administration of the probiotic kefir improves the endothelial function in spontaneously hypertensive rats," Journal of Translational Medicine, vol. 13, no. 1, 2015.

[24] T. Pereira, F. Pimenta, M. Porto et al., "Coadjuvants in the diabetic complications: nutraceuticals and drugs with pleiotropic effects," International Journal of Molecular Sciences, vol. 17, no. 8, p. 1273, 2016.

[25] D. D. Rosa, M. M. S. Dias, Ł. M. Grześkowiak, S. A. Reis, L. L. Conceição, and M. . C. G. Peluzio, "Milk kefir: nutritional, microbiological and health benefits," Nutrition Research Reviews, vol. 30, no. 1, pp. 82-96, 2017.

[26] F. G. Amorim, L. B. Coitinho, A. T. Dias et al., "Identification of new bioactive peptides from Kefir milk through proteopeptidomics: bioprospection of antihypertensive molecules," Food Chemistry, vol. 282, no. 1, pp. 109119, 2019.

[27] K. R. M. Barboza, L. Z. Coco, G. M. Alves et al., "Gastroprotective effect of oral kefir on indomethacin-induced acute gastric lesions in mice: impact on oxidative stress," Life Sciences, vol. 209, pp. 370-376, 2018.
[28] F. S. Pimenta, M. Luaces-Regueira, A. M. M. Ton et al., "Mechanisms of action of kefir in chronic cardiovascular and metabolic diseases," Cellular Physiology and Biochemistry, vol. 48, no. 5, pp. 1901-1914, 2018.

[29] B. F. Klippel, L. B. Duemke, M. A. Leal et al., "Effects of kefir on the cardiac autonomic tones and baroreflex sensitivity in spontaneously hypertensive rats," Frontiers in Physiology, vol. 7, no. 211, 2016.

[30] A. F. Santanna, P. F. Filete, E. M. Lima et al., "Chronic administration of the soluble, nonbacterial fraction of kefir attenuates lipid deposition in $\mathrm{LDLr}^{-1-}$ mice," Nutrition, vol. 35, pp. 100105, 2017.

[31] G. M. McKhann, D. S. Knopman, H. Chertkow et al., "The diagnosis of dementia due to Alzheimer's disease: recommendations from the National Institute on Aging-Alzheimer's Association workgroups on diagnostic guidelines for Alzheimer's disease," Alzheimer's \& Dementia, vol. 7, no. 3, pp. 263-269, 2011.

[32] R. Nitrini, P. Caramelli, C. M. Bottino et al., "Diagnóstico de doença de Alzheimer no Brasil: critérios diagnósticos e exames complementares. Recomendações do Departamento Científico de Neurologia Cognitiva e do Envelhecimento da Academia Brasileira de Neurologia," Arquivos de Neuro-Psiquiatria, vol. 63, no. 3A, pp. 713-719, 2005.

[33] D. S. Knopman, S. T. DeKosky, J. L. Cummings et al., "Practice parameter: diagnosis of dementia (an evidence-based review). Report of the Quality Standards Subcommittee of the American Academy of Neurology," Neurology, vol. 56, no. 9, pp. 1143-1153, 2001.

[34] G. McKhann, D. Drachman, M. Folstein, R. Katzman, D. Price, and E. M. Stadlan, "Clinical diagnosis of Alzheimer's disease: report of the NINCDS-ADRDA Work Group under the auspices of Department of Health and Human Services Task Force on Alzheimer's Disease," Neurology, vol. 34, no. 7, pp. 939-944, 1984.

[35] B. P. Campagnaro, C. L. Tonini, B. V. Nogueira, D. E. Casarini, E. C. Vasquez, and S. S. Meyrelles, "DNA damage and augmented oxidative stress in bone marrow mononuclear cells from angiotensin-dependent hypertensive mice," International Journal of Hypertension, vol. 2013, Article ID 305202, 10 pages, 2013.

[36] M. L. Porto, B. P. Rodrigues, T. N. Menezes et al., "Reactive oxygen species contribute to dysfunction of bone marrow hematopoietic stem cells in aged C57BL/6 J mice," Journal of Biomedical Science, vol. 22, no. 1, 2015.

[37] V. Witko-Sarsat, M. Friedlander, C. Capeillère-Blandin et al., "Advanced oxidation protein products as a novel marker of oxidative stress in uremia," Kidney International, vol. 49, no. 5, pp. 1304-1313, 1996.

[38] M. Reers, T. W. Smith, and L. B. Chen, "J-aggregate formation of a carbocyanine as a quantitative fluorescent indicator of membrane potential," Biochemistry, vol. 30, no. 18, pp. 44804486, 1991.

[39] E. Metchnikoff, "The prolongation of life," Nature, vol. 77, no. 1996, pp. 289-290, 1908.

[40] A. I. Tauber, "Metchnikoff and the phagocytosis theory," Nature Reviews Molecular Cell Biology, vol. 4, no. 11, pp. 897-901, 2003.

[41] J. A. Morris, "Optimise the microbial flora with milk and yoghurt to prevent disease," Medical Hypotheses, vol. 114, pp. 13-17, 2018. 
[42] J. Bienenstock and S. Collins, "99th Dahlem Conference on Infection, Inflammation and Chronic Inflammatory Disorders: psycho-neuroimmunology and the intestinal microbiota: clinical observations and basic mechanisms," Clinical \& Experimental Immunology, vol. 160, no. 1, pp. 85-91, 2010.

[43] T. R. Sampson and S. K. Mazmanian, "Control of brain development, function, and behavior by the microbiome," Cell Host \& Microbe, vol. 17, no. 5, pp. 565-576, 2015.

[44] Y. Kobayashi, T. Kinoshita, A. Matsumoto, K. Yoshino, I. Saito, and J. Z. Xiao, "Bifidobacterium breve A1 supplementation improved cognitive decline in older adults with mild cognitive impairment: an open-label, single-arm study," The Journal of Prevention of Alzheimer's Disease, vol. 6, no. 1, pp. 70-75, 2019.

[45] J. F. Cryan and T. G. Dinan, "Mind-altering microorganisms: the impact of the gut microbiota on brain and behaviour," Nature Reviews Neuroscience, vol. 13, no. 10, pp. 701-712, 2012.

[46] P. Hemarajata and J. Versalovic, "Effects of probiotics on gut microbiota: mechanisms of intestinal immunomodulation and neuromodulation," Therapeutic Advances in Gastroenterology, vol. 6, no. 1, pp. 39-51, 2012.

[47] A. Agustí, M. P. García-Pardo, I. López-Almela et al., "Interplay between the gut-brain axis, obesity and cognitive function," Frontiers in Neuroscience, vol. 12, no. 55, pp. 117, 2018.

[48] C. R. Martin, V. Osadchiy, A. Kalani, and E. A. Mayer, "The brain-gut-microbiome axis," Cellular and Molecular Gastroenterology and Hepatology, vol. 6, no. 2, pp. 133-148, 2018.

[49] A. Baj, E. Moro, M. Bistoletti, V. Orlandi, F. Crema, and C. Giaroni, "Glutamatergic signaling along the microbiotagut-brain axis," International Journal of Molecular Sciences, vol. 20, no. 6, p. 1482, 2019.

[50] F. Leblhuber, K. Steiner, B. Schuetz, D. Fuchs, and J. M. Gostner, "Probiotic supplementation in patients with Alzheimer's dementia - an explorative intervention study," Current Alzheimer Research, vol. 15, no. 12, pp. 11061113, 2018.

[51] N. Sudo, Y. Chida, Y. Aiba et al., "Postnatal microbial colonization programs the hypothalamic-pituitary-adrenal system for stress response in mice," The Journal of Physiology, vol. 558, no. 1, pp. 263-275, 2004.

[52] W. R. Wikoff, A. T. Anfora, J. Liu et al., "Metabolomics analysis reveals large effects of gut microflora on mammalian blood metabolites," Proceedings of the National Academy of Sciences, vol. 106, no. 10, pp. 3698-3703, 2009.

[53] T. Higuchi, H. Hayashi, and K. Abe, "Exchange of glutamate and gamma-aminobutyrate in a Lactobacillus strain," Journal of Bacteriology, vol. 179, no. 10, pp. 3362-3364, 1997.

[54] K. M. Neufeld, N. Kang, J. Bienenstock, and J. A. Foster, "Reduced anxiety-like behavior and central neurochemical change in germ-free mice," Neurogastroenterology \& Motility, vol. 23, no. 3, p. 255, 2011.

[55] J. D. Doecke, S. M. Laws, N. G. Faux et al., "Blood-based protein biomarkers for diagnosis of Alzheimer disease," Archives of Neurology, vol. 69, no. 10, pp. 1318-1325, 2012.

[56] D. Baylis, D. B. Bartlett, H. P. Patel, and H. C. Roberts, "Understanding how we age: insights into inflammaging," Longevity \& Healthspan, vol. 2, no. 1, article 17, 2013.

[57] L. Zuroff, D. Daley, K. L. Black, and M. Koronyo-Hamaoui, "Clearance of cerebral $A \beta$ in Alzheimer's disease: reassessing the role of microglia and monocytes," Cellular and Molecular Life Sciences, vol. 74, no. 12, pp. 2167-2201, 2017.

[58] F. Alasmari, M. A. Alshammari, A. F. Alasmari, W. A. Alanazi, and K. Alhazzani, "Neuroinflammatory cytokines induce amyloid beta neurotoxicity through modulating amyloid precursor protein levels/metabolism," BioMed Research International, vol. 2018, Article ID 3087475, 8 pages, 2018.

[59] C. Franceschi, P. Garagnani, P. Parini, C. Giuliani, and A. Santoro, "Inflammaging: a new immune-metabolic viewpoint for age-related diseases," Nature Reviews Endocrinology, vol. 14, no. 10, pp. 576-590, 2018.

[60] C. Zheng, X. W. Zhou, and J. Z. Wang, "The dual roles of cytokines in Alzheimer's disease: update on interleukins, TNF- $\alpha$, TGF- $\beta$ and IFN- $\gamma$," Translational Neurodegeneration, vol. 5, no. 1, 2016.

[61] N. S. Patel, D. Paris, V. Mathura, A. N. Quadros, F. C. Crawford, and M. J. Mullan, "Inflammatory cytokine levels correlate with amyloid load in transgenic mouse models of Alzheimer's disease," Journal of Neuroinflammation, vol. 2, no. 1, p. 9, 2005.

[62] R. Leung, P. Proitsi, A. Simmons et al., "Inflammatory proteins in plasma are associated with severity of Alzheimer's disease," PLoS One, vol. 8, no. 6, p. e64971, 2013.

[63] J. W. Kinney, S. M. Bemiller, A. S. Murtishaw, A. M. Leisgang, A. M. Salazar, and B. T. Lamb, "Inflammation as a central mechanism in Alzheimer's disease," Alzheimer's \& Dementia, vol. 4, pp. 575-590, 2018.

[64] M. Zarrati, E. Salehi, K. Nourijelyani et al., "Effects of probiotic yogurt on fat distribution and gene expression of proinflammatory factors in peripheral blood mononuclear cells in overweight and obese people with or without weight-loss diet," Journal of the American College of Nutrition, vol. 33, no. 6, pp. 417-425, 2014.

[65] S. Sanaie, M. Ebrahimi-Mameghani, H. Hamishehkar, M. Mojtahedzadeh, and A. Mahmoodpoor, "Effect of a multispecies probiotic on inflammatory markers in critically ill patients: a randomized, double-blind, placebo-controlled trial," Journal of Research in Medical Sciences: the official journal of Isfahan University of Medical Sciences, vol. 19, no. 9, pp. 827-833, 2014.

[66] S. K. Angurana, A. Bansal, S. Singhi et al., "Evaluation of effect of probiotics on cytokine levels in critically Ill children with severe sepsis," Critical Care Medicine, vol. 46, no. 10, pp. 1656-1664, 2018.

[67] L. Migliore, I. Fontana, F. Trippi et al., "Oxidative DNA damage in peripheral leukocytes of mild cognitive impairment and AD patients," Neurobiology of Aging, vol. 26, no. 5, pp. 567-573, 2005.

[68] G. E. Gibson and H. M. Huang, "Oxidative stress in Alzheimer's disease," Neurobiology of Aging, vol. 25, no. 5, 2005.

[69] T. Marcourakis, R. Camarini, E. M. Kawamoto, L. R. Scorsi, and C. Scavone, "Peripheral biomarkers of oxidative stress in aging and Alzheimer's disease," Dementia \& Neuropsychologia, vol. 2, no. 1, pp. 2-8, 2008.

[70] Y. T. Chang, W. N. Chang, N. W. Tsai et al., "The roles of biomarkers of oxidative stress and antioxidant in Alzheimer's disease: a systematic review," BioMed Research International, vol. 2014, Article ID 182303, 14 pages, 2014.

[71] C. Peña-Bautista, M. Baquero, M. Vento, and C. CháferPericás, "Free radicals in Alzheimer's disease: lipid 
peroxidation biomarkers," Clinica Chimica Acta, vol. 491, pp. 85-90, 2019.

[72] M. Naoi, Y. Wu, M. Shamoto-Nagai, and W. Maruyama, "Mitochondria in neuroprotection by phytochemicals: bioactive polyphenols modulate mitochondrial apoptosis system, function and structure," International Journal of Molecular Sciences, vol. 20, no. 10, p. 2451, 2019.

[73] D. M. Williams, S. Hägg, and N. L. Pedersen, "Circulating antioxidants and Alzheimer disease prevention: a Mendelian randomization study," The American Journal of Clinical Nutrition, vol. 109, no. 1, pp. 90-98, 2019.

[74] D. Praticò, "Oxidative stress hypothesis in Alzheimer's disease: a reappraisal," Trends in Pharmacological Sciences, vol. 29, no. 12, pp. 609-615, 2008.

[75] B. Su, X. Wang, A. Nunomura et al., "Oxidative stress signaling in Alzheimer's disease," Current Alzheimer Research, vol. 5, no. 6, pp. 525-532, 2008.

[76] U. Shefa, N. Y. Jeong, I. O. Song et al., "Mitophagy links oxidative stress conditions and neurodegenerative diseases," Neural Regeneration Research, vol. 14, no. 5, pp. 749-756, 2019.

[77] M. Sochocka, B. S. Diniz, and J. Leszek, "Inflammatory response in the CNS: friend or foe?," Molecular Neurobiology, vol. 54, no. 10, pp. 8071-8089, 2017.

[78] E. B. Manukhina, M. G. Pshennikova, A. V. Goryacheva et al., "Role of nitric oxide in prevention of cognitive disorders in neurodegenerative brain injuries in rats," Bulletin of Experimental Biology and Medicine, vol. 146, no. 4, pp. 391-395, 2008.

[79] V. Paul and P. Ekambaram, "Involvement of nitric oxide in learning \& memory processes," The Indian Journal of Medical Research, vol. 133, no. 5, pp. 471-478, 2011.

[80] P. Picón-Pagès, J. Garcia-Buendia, and F. J. Muñoz, "Functions and dysfunctions of nitric oxide in brain," Biochimica et Biophysica Acta - Molecular Basis of Disease, vol. 1865, no. 8, pp. 1949-1967, 2019.

[81] T. Yuan, T. Yang, H. Chen et al., "New insights into oxidative stress and inflammation during diabetes mellitus- accelerated atherosclerosis," Redox Biology, vol. 20, pp. 247-260, 2019.

[82] M. Manczak, T. S. Anekonda, E. Henson, B. S. Park, J. Quinn, and P. H. Reddy, "Mitochondria are a direct site of A beta accumulation in Alzheimer's disease neurons: implications for free radical generation and oxidative damage in disease progression," Human Molecular Genetics, vol. 15, no. 9, pp. 1437-1449, 2006.

[83] I. G. Onyango, J. Dennis, and S. M. Khan, "Mitochondrial dysfunction in Alzheimer's disease and the rationale for bioenergetics based therapies," Aging and Disease, vol. 7, no. 2, pp. 201-214, 2016.

[84] R. H. Swerdlow, "Mitochondria and mitochondrial cascades in Alzheimer's disease," Journal of Alzheimer's Disease, vol. 62, no. 3, pp. 1403-1416, 2018.

[85] L. A. Demetrius, P. J. Magistretti, and L. Pellerin, “Alzheimer's disease: the amyloid hypothesis and the Inverse Warburg effect," Frontiers in Physiology, vol. 5, no. 522, 2015.

[86] A. Delbarba, G. Abate, C. Prandelli et al., "Mitochondrial alterations in peripheral mononuclear blood cells from Alzheimer's disease and mild cognitive impairment patients," Oxidative Medicine and Cellular Longevity, vol. 2016, Article ID 5923938, 11 pages, 2016.

[87] D. Liu and Y. Xu, "p53, oxidative stress, and aging," Antioxidants \& Redox Signaling, vol. 15, no. 6, pp. 1669-1678, 2011.
[88] K. Beyfuss and D. A. Hood, "A systematic review of p53 regulation of oxidative stress in skeletal muscle," Redox Report, vol. 23, no. 1, pp. 100-117, 2018.

[89] S. Kaczanowski, J. Klim, and U. Zielenkiewicz, “An apoptotic and endosymbiotic explanation of the Warburg and the inverse Warburg hypotheses," International Journal of Molecular Sciences, vol. 9, no. 10, p. 3100, 2018.

[90] G. Chaitanya, J. S. Alexander, and P. Babu, "PARP-1 cleavage fragments: signatures of cell-death proteases in neurodegeneration," Cell Communication and Signaling, vol. 8, no. 1, p. 31, 2010. 


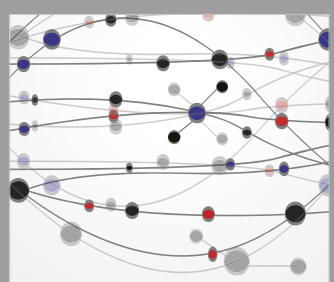

The Scientific World Journal
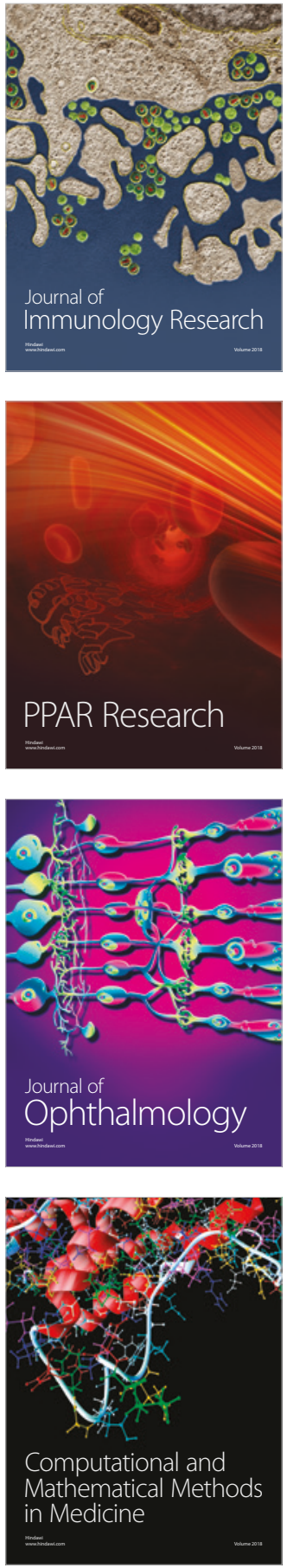

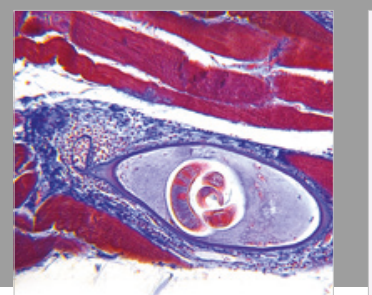

Gastroenterology Research and Practice

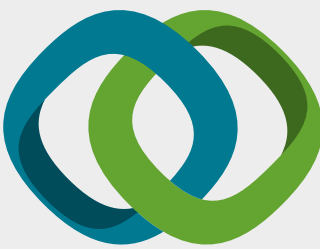

\section{Hindawi}

Submit your manuscripts at

www.hindawi.com
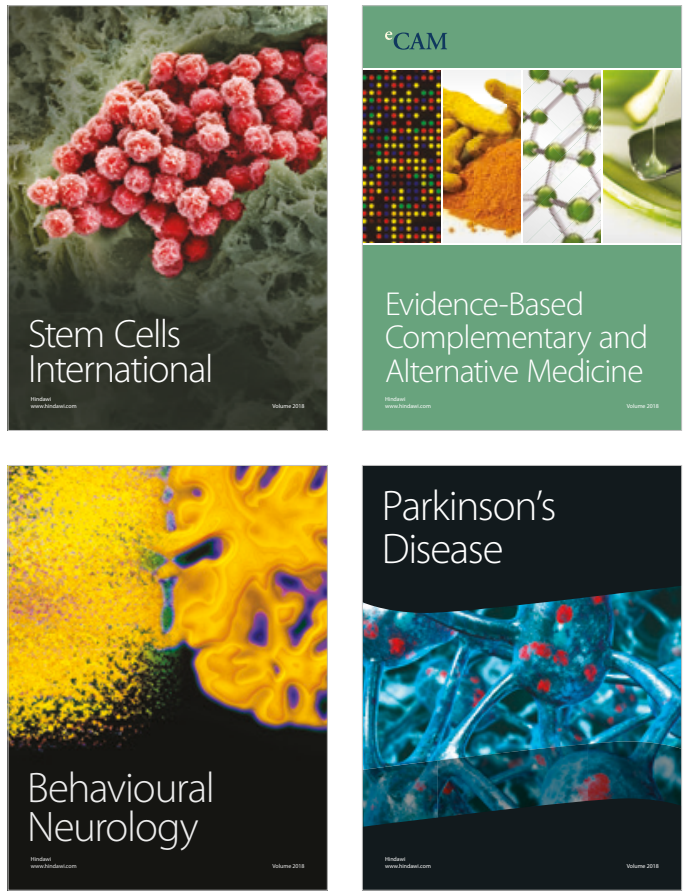



ournal of

Diabetes Research

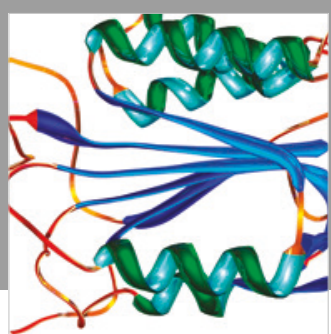

Disease Markers
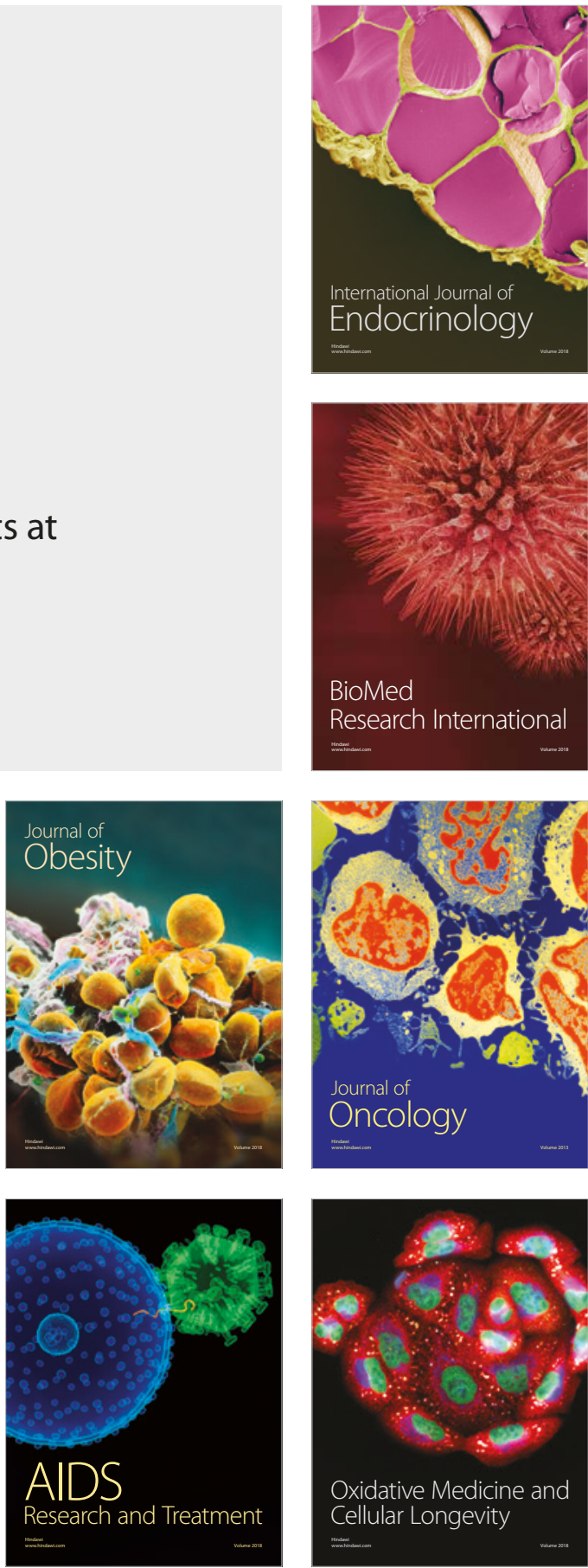